Article

\title{
Sustainable Refugee Migration: A Rethink towards a Positive Capability Approach
}

\author{
Mohammed Al-Husban ${ }^{1,+}$ and Carl Adams $2, *,+$ \\ 1 School of Media Arts and Technology, Southampton Solent Unuviersity, Southampton SO14 0YN, UK; \\ Mohammed.Al-Husban@solent.ac.uk \\ 2 School of Computing, University of Portsmouth, Portsmouth PO13HE, UK \\ * Correspondence: carl.adams@port.ac.uk; Tel.: +44-23-9284-6447 \\ + These authors contributed equally to this work.
}

Academic Editors: Giuseppe Ioppolo, Isabel Ramos and Rui Dinis Sousa

Received: 1 December 2015; Accepted: 22 April 2016; Published: 6 May 2016

\begin{abstract}
A major challenge facing many countries around the world is how to sustainably address the issues of increased numbers of refugee migrants. The refugee migrant "issue" is often heavily political as a high density of migrants in local areas impacts communities (e.g., disrupting local employment, service and culture). Different migrants come with different "baggage" and needs which can be a significant draw on the hosting communities' resources. This paper argues that sustainable long-term solutions to refugee migrants will require a rethink to the existing dominant models of containment and charity. The paper draws upon insights from a study of a large refugee camp in Jordan over a three-and-a-half-year period, and historical cases of refugee migration. The paper presents a sustainable model that develops long-term capability for the various stakeholder groups.
\end{abstract}

Keywords: sustainable; migration; refugees; positive capability approach

\section{Introduction}

This discussion hopes to challenge the prevailing model and response to the waves of mass refugee migrants around the globe which seem to be considering the issues within a charity and containment problem space. Mass migration by refugee migrants is invariably seen as a short-term "problem" that will consume resources and generally have a negative impact on the hosting communities. This paper explores moving towards sustainable approaches to migration which will require some rethinking and reframing from a short-term problem arena.

Migration has been the normal state of human and economic history throughout human evolution [1]. In recent centuries, during the 1800s we saw mass migration from rural to urban areas in many countries at the forefront of the industrial revolution. This urban migration has continued since then, especially in nations going through sustained economic development such as the BRIC (Brazil, Russia, India and China) and MINT (Mexico, Indonesia, Nigeria, and Turkey) countries. Evidence for this can be found in the United Nations World Urbanization Prospects report for 2014 which indicates more people are living in urban areas than in rural areas, with an expectation on the current trajectory that two-thirds of the world's population will be in urban areas by 2050 [2].

Some countries such as the USA were built on migrant populations in centuries past. Often it is some of the most able and capable people that undertake migration to new pastures-the budding entrepreneurs who are able to contribute to economic development. Of course, such migration raises many problems for the various communities impacted. The countries and communities of origin can often be devastated as they lose key skill sets and people within their communities. For instance, in Japan, where there are low birth rates and an aging population, many rural communities are turning into ghost towns as the younger people move to the big cities with all the attractions they offer. Some 
of the communities in Eastern Europe are facing similar problems as significant numbers of talented young people join economic migrants to find jobs in other parts of Europe.

Migration takes on a more immediate dimension when it is a response to a disaster or geopolitical instability, and it often results in large numbers of migrants, or a mass migration event. The immediate response to mass migration is often containment where large numbers of migrants are corralled together while various hosting communities try to work out what to do with the influx of large groups of people. The charity side to the model is effectively throwing humanitarian resources at people clearly in need of the bare necessities to maintain life for displaced people, such as water, food and shelter. These responses are fairly short-term and reactive in nature, responding to events after they have happened. However, mass refugee migration is not a new phenomenon and some planning and preparedness can alleviate some of the main challenges and problems.

Dealing with waves of migrants has tested many countries around the world [3]. For instance, in Southeast Asia there has been a migrant crisis with Rohingya refugees who have fled persecution and loss of statehood in Burma, impacting local countries and communities in Indonesia, Malaysia and Thailand, and further afield in Australia [4]. Interlinked with the refugees, there are often economic migrants trying to get employment and a better life, in this case the Bangladeshis mingled with the Rohingya refugees. The Guardian, reporting on a regional meeting in Bangkok in May 2015, in response to thousands of refugee and economic migrants being stranded and abandoned at sea in the region, shows some of the complexity of the problem space:

"Malaysia and Indonesia agreed last week to provide the migrants shelter for one year. Indonesia says Rohingya can stay for a year but Bangladeshis will be repatriated. It is unclear what happens after a year, and both countries have called on the international community to help with resettlement options.

Thailand has offered humanitarian help but not shelter. More than 100,000 refugees, mostly from Burma's other ethnic groups, have been living in border camps for decades, and Thailand says it cannot afford any more." [4].

The response to the Rohingya and Bangladeshi migrants from Malaysia and Indonesia is fairly typical in that they try and offer a safe haven for the Rohingya refugees, in this case for a limited time while hopefully longer-term solutions for the refugees can be worked out, in which the refugees' origin country of Burma may have a role to play. In addition, their response to the Bangladeshi migrants is treated differently with more immediate repatriation.

Refugee migration is an international problem and the international community has some responsibility and a role to play. We can learn and relearn this lesson from history. For instance, in the 1970s there was also a major refugee migration crisis event after the Vietnam War period involving over a million people coming from three Indochinese countries: Vietnam, Cambodia, and Laos. Larry Thompson's book [5] covers much of the turbulence through this period and the resulting mass Indochina exodus. A large proportion of these refugees went to Thailand, a relatively poor country, which itself was going through a period of unrest with the Thai government being lead by General Kriangsak Chomanan who came to power after a military coup. The Thai government asked for aid and support from the international community, which was somewhat lacking. This was the time of civil war in Cambodia with the Vietnamese army invading to overthrow the Khmer Rouge. The burden of looking after and feeding such large numbers of refugees-along with feeding its own population-coupled with the potential geopolitical unrest led to a fairly drastic measure with the Thai government expelling over 40,000 Cambodian refugees. One of the main forced expulsion events was around the Preah Vihea Temple situated at the top of a 2000-foot-high cliff-like escarpment overlooking the Thailand-Cambodia border. For those that were able to climb down the escarpment, there was further peril with a stretch of landmines at the base, followed by facing the Vietnamese soldiers occupying Cambodia at the time. Thousands died in this forced expulsion. This brutal and desperate measure by the Thai government did result in the international community taking some 
responsibility in such mass refugee events; indeed, for over a decade after the event the UN and Western countries contributed towards the upkeep of Cambodian refugees in Thailand and helped with resettling refugees in other countries and worked towards safely resettling Cambodian refugees back to their own country [5] (p. 178).

Sometimes a refugee crisis can be long term, for instance the Palestinian refugees in Lebanon and Jordan as a result of the 1948 Palestine War, which saw over 700,000 people displaced into adjoining countries. These Palestinian refugee camps in Jordan are now home to second- and third-generation "refugees" who are now really integrated members of the host communities.

There are many messages to learn from such incidents of mass refugee migration. One is the potential strain it puts on the local surrounding countries and communities, especially if they have limited resources or have their own areas of unrest. Another is that longer-term solutions and thinking are needed to address the mass migration of refugees. This long-term thinking, we argue, does not fit well with the short-term "containment and charity" approach that seems to be the dominant model to manage the refugee crisis. We suggest that more sustainable and positive strategies can result in win-win situations for the different stakeholder groups involved, such as the refugees migrants themselves, the hosting communities, the countries of origin and the wider international communities. We base this proposition on the analysis of a three-and-a-half-year ethnographic action research study of a refugee camp in Jordan, which is described in the next sections. This paper provides complementary positive views of migrants coverd in other works, notably [6,7].

This paper argues that only very few efforts have been made to enable refugees to support themselves and develop self-sustaining livelihoods, which, if not developed at certain points through the refugee camp lifecycle, will undermine the refugees' livelihood skills, make repatriation more difficult, and increase tensions with the host communities.

\section{Research Method}

An in-depth case study was used in this research, focusing on the Zaatari refugee camp in Jordan, using ethnographic action research. The initial focus for the research was on the integration of services; however, the focus changed to the evolution of the camp over time as it rapidly grew in size and complexity. The in-depth case study provided the ability to explore emerging issues from the various stakeholder groups active in the camp, namely government agencies, Non Government Organizations (NGOs) and refugees. The research is informed with 15 interactive focus groups and over 60 interviews conducted over five field trips in the period between August 2011 and December 2014. Data was recorded and transcribed for analysis. More details of the research method, analysis, interaction between stakeholder groups and evolving processes within the camp are covered elsewhere [8].

\section{The Refugee Camp: The "Camp to City in Little Time" Case of the Zaatari Refugee Camp}

In 2011, as a result of the Arabic spring and the political unrest in Syria, and since because Jordan is the closest country in social, religious and economic terms, it has seen a good deal of Syrian migration, with around 320,000 refugees fleeing within that year, with numbers now reaching well over a million refugees $[9,10]$.

The Zaatari camp was officially inaugurated on 28 July 2011, and its basic structure was constructed in just nine days to initially house 100 families; however, after unprecedented exponential growth, it is currently the second largest refugee camp in the world [11]. It is now home to over 120,000 Syrian refugees, including many children unaccompanied by parents. It is becoming an active and growing "city", for instance there are around 13 babies born there every day. The vast majority of the refugees were formerly residents of the southern Daraa Governorate in Syria, where artillery air attacks first took place. The Zaatari camp is located in the Mafraq Governorate in northern Jordan, and still suffers severe issues in terms of macroeconomic, social, and health conditions and service provision. The living conditions in the camp are improving but still certainly hazardous [12]. 
As demonstrated in Figure 1, the Zaatari refugee camp has gone through tremendous influx in terms of size and population, and as a result, four phases have been identified from 2012 to 2014, namely the manic phase, the just-in-time bureaucracy phase, the semi-structured phase and the structured and sustainable phase.

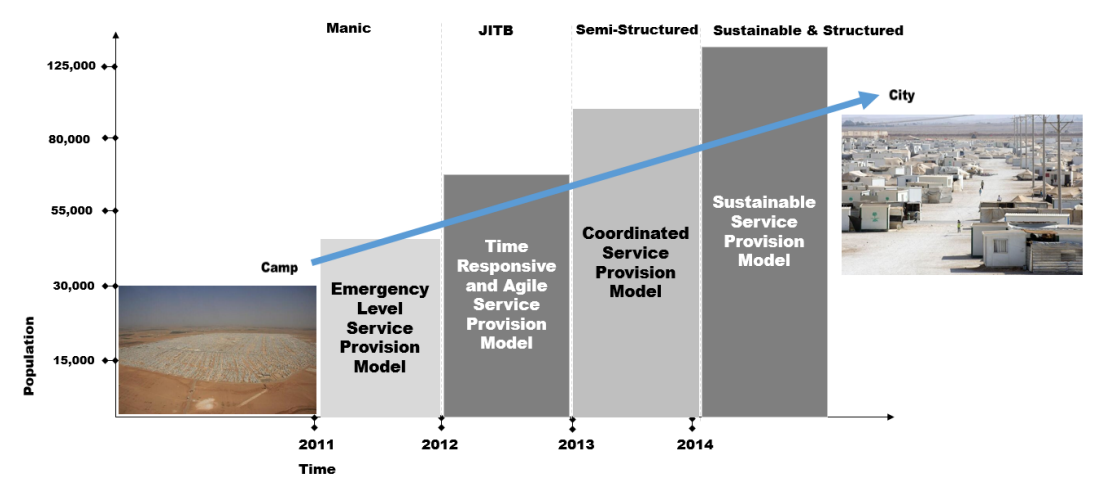

Figure 1. The growth of the Zaatari refugee camp.

Over the last few years, the Jordanian government has pursued actions to prevent the influx from having too much of an effect on the living standards of Jordanians and political stability in the Kingdom through various measures, and these measures have largely set the parameters for the international humanitarian response. In order to prevent a more permanent settlement, refugee registration has been limited to six months (renewable). In order to reduce the impact of the refugee population in the cities, in July 2012 the government approved the establishment of a large refugee camp at Zaatari (and has approved another to be opened at Azraq), which has since housed all refugees upon immediate arrival and much of the overall refugee caseload. Additionally, in order to reduce the drag on its own resources, the government invited the international community to fund and support the response and the UNHCR to co-manage it.

The overwhelm number of refugees had a significant impact on the Jordanian government and society, affecting their capacity and ability to cope with their national population's needs and the refugee's needs. In 2013, Syrians accounted for 7\% of the country's population [10]. Syrian refugees have continually increased in number and are becoming a significant part of the Jordanian life and community.

The human capital embedded within the refugee camp during this research was phenomenal, where the refugees' resilience and desire to live and prosper emerged in spite of the tremendous political, economic and psychologically difficult conditions. Inside the camps, buildings and structures emerged along with economic activity, leading towards many businesses and new "camp business models" with many groups being self-sufficient. The Zaatari refugee camp became a city with a main commercial street offering a variety of retail outlets including food, groceries, mobile phones, technology and a wedding dress shop. Each new wave of refugees brought a new set of skills and new business start-ups. The Zaatari camp now hosts more than 3000 different shops and businesses. The camp's economic activity extends outside the camp with a travel agency, pizza delivery service, and more interestingly, a fine bakery, the Damshqi Bakery (Figure 2), providing a good example of outreach capabilities providing trade to many in the local host community. The small-scale entrepreneurs are currently generating an estimated 10 million Jordanian dollars in revenue per month. The Ministry of Trade and Commerce reported that an estimated $60 \%$ of the refugee population earns some form of income within the camp.

In the host community, the city of Mafraq, Syrians have been filling positions that local Jordanians do not want, working as waiters and cleaners and in other lower-paid jobs or jobs less highly thought of by the locals. The refugees were earning a living with dignity, providing for their families and at the same time being productive in the host country. 

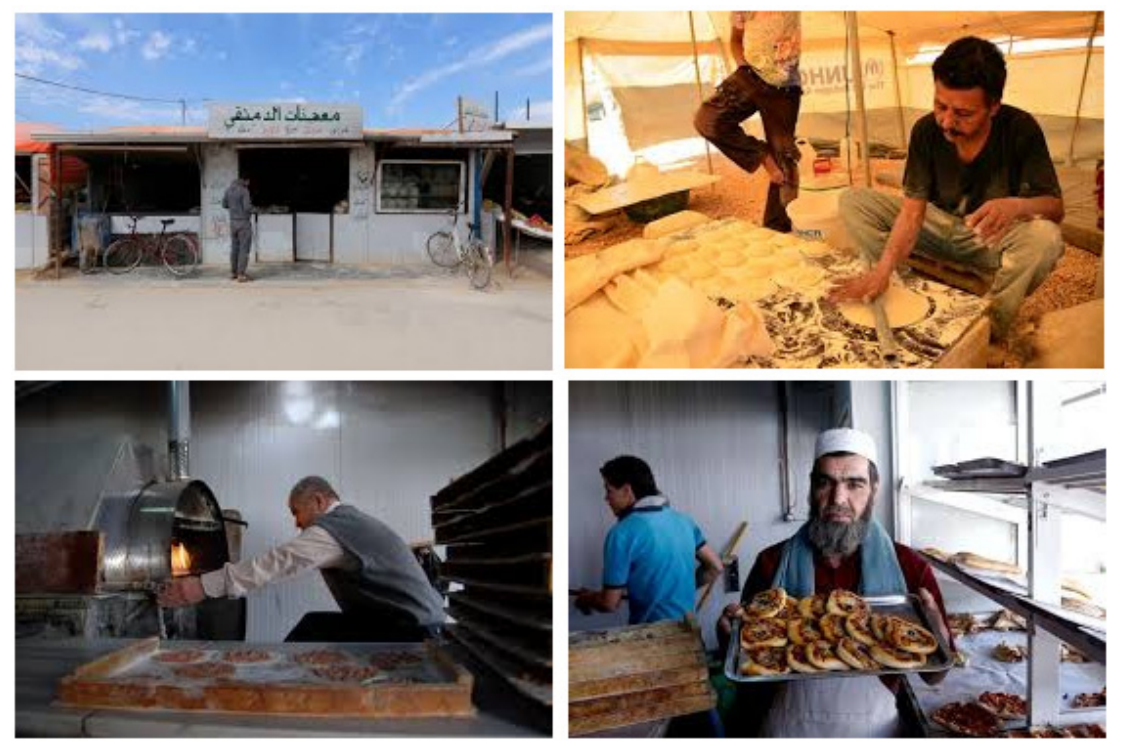

Figure 2. Economic activity within the camp.

The NGOs, government agencies and wider stakeholder groups made tremendous efforts to help with the evolution of the camp and to deal with the often chaotic, changing needs and focus within the camp community.

The sudden influx of Syrian refugees in the Zaatari camp, alongside relief resources and International Non-Government Organizations in Jordan, has significantly altered the lives of people who lived there. There were clearly conflicts, challenges and many growing pains as the camp rapidly evolved, affecting not only the camp community but also the surrounding host communities. There were also opportunities for the host communities resulting in positive changes as well. With the increased local market, there was an upsurge in business and trade conducted by both local hosts and refugees. Jordanian entrepreneurs from around the country also flocked to the area. Commercial centers developed in the refugee camps with daily markets and countless shops and restaurants. The largest of these centers was at the Zaatari camp, which was transformed from an intersection with a one-stop shop into a massive shopping mall. In many cases, refugees were perceived by local host people as better at doing business than Jordanians themselves.

There was also an improvement in information provision, knowledge and expertise within the wider camp community, particularly in medical and educational services, with the influx of high quality services by international contributors. The host community has greatly benefited from different levels of expertise provided by operational partners and NGOs operating in the Zaatari refugee camp. Doctors have explicitly described this as international collaborative effort geared towards helping refugees, which in turn has helped in sharing medical practical experiences, not only in dealing with critical situations, and has had its own positive implication in improving the quality of health services provision in local and national hospitals and health centres. This knowledge and expertise increase has also benefited the educational sector in the local and host communities, not only through student engagement but also by sharing experiences across and between different educational agencies in and outside the camp.

\section{Main Lessons from the Zaatari Refugee Camp}

There are, of course, still many challenges in integrating the refugee camps within Jordan, such as changes to the culture and the potential for instabilities within the small country. However, one of the key messages is that the Zaatari refugee camp did not provide all negative experiences for the local host community and Jordan, more generally. Economically, the local region developed along with the wider local skill sets as a result of the camp. The charity model worked for a short period, as 
too did the containment model; however, the camp residents fairly quickly were taking active roles and working towards being a self-reliant, contributing and sustainable community. The next section will explore other themes to help achieve this state of self-reliance for the refugees at the same time as making a positive contribution to the local host communities.

The camp environment was very complex and affected by many geopolitical influences. For instance, there were clearly challenges for many of the Middle Eastern medical and humanitarian actors actively involved and responding to emergency situations, taking into account both the political dimensions of the aid response and the technical needs of such emergencies. Many of the staff sent to work in Jordan were technical staff and they may not have had skills to engage with the wider issues relating to allocations of aid or political bias. Others had been accused of having a political or religious bias, providing assistance only to veiled women, for example. Many organizations have also been accused of seeking to make donations that have "visual impact", for example taking photos with wounded people, or showing off infrastructure projects. Further, some health actors were not very experienced in refugee health and the specific approaches within it. There has been some criticism that they lack an emergency public health perspective, as they have doctors coming in from wealthy countries and running their clinic as they would at home, without much regard for the specific risk factors in a refugee setting. There has been a significant mobilisation of many organizations which can be considered "new" or "emerging" humanitarian actors, as they only have limited experience in working in humanitarian contexts, and do not participate in the existing system structures. Most of these have come from within the Muslim world, and especially within the Middle East, as a demonstration of Muslim unity and Arab solidarity. Any criticisms aside, there was clearly a significant groundswell of support from many agencies and contributors from both Middle Eastern communities and from the wider international communities.

The general consensus is that these organizations and agencies addressed important needs in response to the huge humanitarian crisis, with different actors providing different support. Some have large amounts of flexible and disposable cash for funding humanitarian activity, which means they can respond to needs as they arise, without many of the pre-conditions of the traditional aid system. They are in some ways also more adapted to middle income settings as they are willing to fund existing health services, for example, or set up partnerships with private health providers, rather than set up completely parallel structures. For other actors there were no problems with their cultural acceptability toward the Syrian refugee population. Collectively, these emerging actors challenge existing humanitarian systems and models in other parts of the world by bringing in a new dynamic. Each major humanitarian disaster and corresponding response in refugee issues will likely have unique characteristics, though there may be general themes that can be applied to multiple examples.

Refugees generally face repatriation to a post-conflict situation in which the rehabilitation of their home communities will be a long and difficult process. Once uncertainty has declined and the political unrest settles, refugees are expected to return to their homeland. However, Syrian refugees repatriating to Syria can expect to find minimal public services, education and health care at home. As time goes on, indications from this research show that the volume of services in the camp exponentially decreases, and the camp starts to suffer from donor fatigue; therefore, sustaining the same level of services as is seems to be impossible, as other crises are happening in another part of the world and the donors' attention is shifted elsewhere. This donor fatigue, over time, will likely affect other major refugee camps regardless of location, so sustainability, resilience and self-reliance must be developed within the camp and local host community.

Semi-permanence and uncertainty are two key primary issues currently affecting the camp management and also the service provision model. As the Syrian conflict has stepped into its fourth year, the statehood of the Syrian refugees in the long run is debatable. Asylum is fundamentally a protective measure, and international refugee law is intended to give asylum to those who have a legitimate fear of persecution or of being caught up in a situation of generalized violence. In either case, once the conflict ends and security is restored in Syria, perhaps there is no longer a strong protection 
argument for why the refugees continue to require asylum and stay in the camp. If a large part of the reason for not returning is that economic conditions are difficult and the home country cannot provide adequate social services, then the basis for asylum is much harder to justify, particularly when the host country also has extensive economic problems, as Jordan does. The idea that refugees can wait to return until their towns are rehabilitated can also harm their home communities by reducing the amount of reconstruction aid they receive. In a post-conflict rehabilitation context, aid is not generally delivered to abandoned towns; rather, it is directed to the areas where people are returning in the highest numbers. There is a need to maintain and develop capability in the refugee communities, and some self-reliance, to enable them to eventually return to their places of origin and rebuild their towns and communities.

The transition of refugees into the host community from the refugee camp raised several areas of contention. For instance, the unpredicted influx of refugees in a very short time placed a critical pressure on social, economic, institutional and natural resource systems' capacities to cope. Host communities around the camps were impacted by different degrees, and ,more importantly, citizens' rightful access to quality public services was dramatically affected, especially in the governorate of Mafraq, the local town by the camp. People in Mafraq found themselves confronted by additional competition with Syrians in the local job markets, with a worrisome increase in child labour, which put more pressure on local wages and caused food, fuel and rent price inflation. As part of the international effort to contain the crisis, the Jordanian government granted access to local public services for Syria refugees, including educational services, schooling, health care and social services. However, these efforts came with increasing pressure and strain on the local public services and infrastructure, some of which were already previously deficient in quality or inadequate in capacity to meet the needs of the local pre-crisis population.

Maintaining the balance of the level of assistance for the refugees and for the host population is key in managing refugee camps. This is likely to be the same in many refugee camps that interact with local communities. The traditional approach to refugee assistance pays lip service to the inclusion of the host community in assistance endeavours, but in Jordan and many other contexts, this is not a major consideration for humanitarian actors. A far better alternative would be to balance the levels of services available to both populations while engaging the host population in the provision of services to the refugees. Indeed, where integration worked well was when there was a win-win situation for both the refugees and the local communities. One good example of this was with the health care and hospital provision mentioned above. In the case of hospital services for the refugee camp, the result was an influx of international medical expertise including doctors, nurses, surgeons and medical specialists who interacted with the local hospital and medical communities. In tight coordination with the Jordanian Ministry of Health, numerous facilities provide primary health care, including clinics administered by the Ministry, the Jordan Health Aid Society, and the Saudi government. In the camp, secondary care is being supplied through the Moroccan and Jordan-Italian military field hospitals. Tertiary care needs are referred outside the camp to the hospital in Mafraq. This sharing of expertise has a significant positive impact on the local hosting community. Further, this is supported by much international funding from, among others, the United Nations Office of the High Commissioner for Refugees (UNHCR), UNICEF, the United Nations Population Fund (UNFPA), Médecins du Monde (MDM), Médecins San Frontières (MSF) and the WHO.

This model of working towards enhancing local support mechanisms in part funded by international bodies seems to be a good approach to achieve a win-win situation for the various stakeholders [13]. This would decrease tensions between the two groups, while creating a concrete incentive for the host population to be more welcoming to the refugees. The example of improving the overall provision of health services would likely be applicable to other regions (in parts of Africa and Asia for instance). Assistance could be structured to increase the local capacity to handle the additional caseload, in conjunction with programs to enhance the quality of services for the hosting nation. This would provide tangible benefits to the host community, ensure a comparable level of services for 
refugees and the host population, and avoid the need to construct a costly and unsustainable parallel health care system for the refugees.

\section{Discussion and Conclusions}

The discussions earlier argue that the international community has a role to play in supporting mass refugees. Meilaender [14] argues that states may exercise "wide discretion" in their immigration policies reflecting their own community, resources and political visions, implying that different states would support the mass refugees in different ways. For instance, some states would legitimately meet their international obligations by providing funds, while others may provide expertise or other resources, while others may provide more direct hosting support for the refugees. Examples of these different supports from different countries and entities were clearly evident in the Zaatari refugee camp example.

Discussions earlier covered the charity mindset present typically during the early stages of a disaster crisis. One challenge is how to use that aid most productively, and debate often focuses around the "aid vs. trade" approaches to development and which would be most useful within an evolving refugee camp context. In 1954, President Eisenhower initiated the Food for Peace [10] program, sending much needed food supplies to many communities around the world going through some harsh economic and environmental conditions at the time. Though there are often criticisms of such programs, such as that the aid often comes with strings attached and often it was surplus food produced by farmers in the USA, we can rightly celebrate the generous donation of food aid by the USA and others, and clearly such aid has saved many millions of lives around the world. Christopher Barrett [15] from Cornell University looked at the impact of this food aid on the stability of the food supply within poor countries. His results indicate that food aid was helpful in averting humanitarian disasters in the short term but that it destabilises and distorts the local food supply, potentially making the local communities less able to cope in the longer term; it was pointed out particularly that the flooding of cheap food aid would distort local competition, pricing out local producers and thus reducing local production capabilities as well as local food variety.

In addition, the large food aid programs are often not efficient in targeting funds to food aid, for instance as Alan Bjerga identifies: “The U.S. ships 2 million tons of corn, soybeans, peas, and other commodities annually to feed 53 million people overseas at a cost of about $\$ 2$ billion. Only 40 cents of every dollar spent, on average, goes toward food" [16].

An alternative approach to food aid has been suggested by the Obama administration which wants to switch the authority for spending on food aid from the U.S. Department of Agriculture to the U.S. Agency for International Development, thus reducing funds for American crops while trying to purchase food from farmers closer to where it is being distributed [16]. This would bring local capability, opportunity and employment to host countries and communities, which ties in very much with the messages from the Zaatari refugee camp (i.e., using skills and resources from the local host community). A further extension to this would be to use the human capital within the camp as well as part of the support package.

Sustainable thinking for refugee camps requires wider consideration on incorporating the local host communities. Such thinking would consider how to support local food production, local commerce, local development needs, etc., as well as the camp's needs. It should also include considering the camp residents as active agents that also have a role to play in obtaining self-reliance and contributing to the local host community. We must effectively look at how we can develop capability and opportunity in the refugee camp communities so they can become positive self-reliant contributors within the host communities in the long term or be able to repatriate when opportunity arises.

Sustainability involves looking for long-term, resilient solutions that set in place processes, structures and systems that can accommodate change as the problem space evolves. The paper draws upon insights from a refugee camp in Jordan as it evolved from a camp of a few thousand people to a city of over 120,000 people. One of the key insights from the refugee camp was that it was a hive of 
human capital and capability, resulting in the camp emerging as a functioning entity with a bustling economy. There are many problems, challenges and areas of tension between the camp and local communities, but there are also many areas where the camp was making a positive contribution to the local economy. Examining routes and options to fully use the human capital within such a camp provides pointers to how other groupings of refugee migrants can be facilitated towards providing positive contributions to the local host communities. Perhaps also looking at the needs of potential local host communities may point to where refugee camps would be best placed, for instance in places where there is a need for labour or skills or capability, say in building a new hospital or infrastructure. For the refugees, working towards being self-reliant and engaging fully within a community is far more preferable than just being the receivers of charity food; indeed, the refugee communities do invariably work towards being members of an active community.

For many refugees the ultimate aim is repatriation, going back to their home land when/if the crisis is resolved, by which time a positive contributing approach would lead to the repatriated people having developed skills sets, a knowledge base and capabilities. For the refugee/migrant countries of origin, there is likely to be significant positive potential, as the returning people would bring much-needed skills and capability to help rebuild the economy. The international communities have their own roles to play, covering diverse types of support from financial, food, knowledge, expertise, and other resources. The contributing international community would also have something to gain as well, by providing stability in the region, and increasing economic activity and longer-term trading potential.

For all stakeholder groups (the refugees/migrants, the local host communities, the refugee/ migrant countries of origin and the international communities), having a sustainable and positive approach to the refugee/migrant "problem" would seem to offer win-win solutions.

Economic migrants are often treated differently to refugees. However, the plight of some of the economic migrants may not be too different to that of the refugees. Take, for instance, the Bangladeshi economic migrants mixed in with the Rohingya discussed earlier. In this case, the Bangladeshis are likely coming from a very deprived context with few opportunities. They have taken drastic measures to better their lives, and perhaps some of them are not in a position too dissimilar from refugee migrants. The potential for migrants to contribute to host communities has been noted by others $[6,7,17]$. In addition to the mass migration of refugees, we also see the mass migration of economic migrants. Perhaps some of the insights from the refugee context can be applied to economic migrants, notably the potential for win-win solutions using and developing the capability of the migrants to make a positive contribution to local host communities. Repatriation could still be a major part of the equation, though it could come after there has been some development of the migrant and hosting communities.

Mass and sustained migration, of both refugee and economic migrants, is often treated in a negative light, yet the reality is that there is significant potential for migration to be a positive activity for the various stakeholders, including the countries of origin, host countries and communities, the migrants themselves and the wider global society.

Given the current geopolitical climate in many parts of the world, with instabilities in various countries and regions, the desire for economic improvement in poorer communities in the world, and the impact of impending disasters as we move into a period of global warming, it is likely that the need for sustainable and resilient solutions for the refugee and migration issues will task policymakers for many years to come. Hopefully the discussion and insights in this paper will inform such policymakers.

Acknowledgments: The authors would like to thank the anonymous reviewers for their detailed, insightful and constructive comments which have helped develop the paper.

Author Contributions: The paper was produced with close collaboration between the authors, Mohammed Al-Husban and Carl Adams. Carl Adams drafted the initial version of the paper with Mohammed Al-Husban providing detailed description and analysis of the primary study from the refugee 
camp and other aspects of the paper. The primary research at the refugee camp was designed and conducted by Mohammed Al-Husban with input from Carl Adams. The historical and global context of refugees was mostly provided by Carl Adams informed with input from Mohammed Al-Husban. The ideas and themes in the paper come from joint discussions and analysis of the context, literature review, global data collected and evaluation of the primary data from the case study by both Mohammed Al-Husban and Carl Adams. All authors read and approved the final manuscript.

Conflicts of Interest: The authors declare no conflict of interest.

\section{References}

1. Times. Times Atlas of World History; Times Books: New York, NY, USA, 2000.

2. UN. 2014 Revision of the World Urbanization Prospects. Available online: http://www.un. org/en/development/desa/publications/2014-revision-world-urbanization-prospects.html (accessed on 12 September 2015).

3. U.S. Agency for International Development. Celebrating "Food for Peace" 1954-2004; U.S. Agency for International Development report: Washington, DC, USA, 2004.

4. Guardian. South-East Asia Migrant Crisis: Numbers Are Now “Alarming”, Talks Told. Friday 29 May 2015. Available online: http://www.theguardian.com/world/2015/may/29/south-east-asia-migrant-crisisnumbers-are-now-alarming-talks-told (accessed on 13 November 2015).

5. Thompson, L.C. Refugee Workers in the Indochina Exodus, 1975-1982; McFarland \& Co.: Jefferson, NC, USA, 2010.

6. Ottaviano, G.I.P.; Peri, G. Rethinking the Gains from Immigration: Theory and Evidence from the U.S. FEEM Working Paper No. 52.06, 2006. Available online: http://dx.doi.org/10.2139/ssrn.896667 (accessed on 5 September 2015).

7. Manacorda, M.; Manning, A.; Wadsworth, J. The impact of immigration on the structure of wages: Theory and evidence from britain. J. Eur. Econ. Assoc. 2012, 10, 120-151. [CrossRef]

8. Al-Husban, M. Digital Public Service Integration in Refugee Camp: Camp to City, Just in Time Bureacracy. Ph.D. Thesis, University of Portsmouth, Portsmouth, UK, 2015.

9. Hall, M. The Syrian Crisis in Jordan. Middle East Research and Information Project. 2103. Available online: http://www.merip.org/mero/mero062413 (accessed on 25 April 2016).

10. Coutts, A.; Fouad, F.M. Response to Syria's health crisis-Poor and uncoordinated. Lancet 2013, 381, 2242-2243. [CrossRef]

11. Mills, D. Aussies diplomat's incredible photos of the crisis in Syria ... and how he gave up a cosy office to make a difference. Daily Mail, 1 July 2014.

12. Olwan, M.; Shiyab, A. Forced Migration of Syrians to Jordan: An Exploratory Study; Migration Policy Centre (MPC): Badia Fiesolana, San Domenico Di Fiesole, Italy, 2012.

13. Ioppolo, G.; Cucurachi, S.; Salomone, R.; Saija, G.; Shi, L. Sustainable Local Development and Environmental Governance: A Strategic Planning Experience. Sustainability 2016. [CrossRef]

14. Meilaender, P.C. Toward A Theory of Immigration. Palgrave MacMillan. 2001. Available online: http:/ / www.palgraveconnect.com/pc/doifinder/10.1057/9780312299118 (accessed on 12 January 2016).

15. Barrett, C.B. Does food aid stabilize food availability? Econ. Dev. Cult. Chang. 2001, 49, 335-349. [CrossRef]

16. Bjerga, A. Obama Wants More Food Aid to Be Locally Sourced. Bloomberg, 25 April 2013. Available online: http:/ / www.bloomberg.com/bw/articles/2013-04-25/obama-wants-more-food-aid-to-be-locallysourced (accessed on 13 November 2015).

17. Esser, H. Does the "New" Immigration Require a "New" Theory of Intergenerational Integration? Int. Migr. Rev. 2004, 38, 1126-1159. [CrossRef]

(C) 2016 by the authors; licensee MDPI, Basel, Switzerland. This article is an open access article distributed under the terms and conditions of the Creative Commons Attribution (CC-BY) license (http://creativecommons.org/licenses/by/4.0/). 